Cardiology 1979;64:I-VI

\title{
Contents, Vol. 64, 1979
}

\section{No. 1}

Original Paper

Richardson, J.W.; Anderson, F.L., and Tsagaris, T.J.: Rest and Exercise Hemodynamic Studies in Patients with Isolated Aortic Stenosis 1

Chagrasulis, R.W. and Urschel, C.W.: Effects of Sodium Nitroprusside on Function of Regional Ischemic Myocardium 12

Punsar, S. and Karvonen, M.J.: Drinking Water Quality and Sudden Death: Observa tions from West and East Finland 24

Degré, S.; Lenaers, A.; Messin, R.; Vandermoten, P.; Salhadin, Ph.; Limage, M., and Denolin, H.: Postinfarction Exercise Capacity after Lidoflazine Treatment or

\section{Physical Training 35}

Pileggi, F.; Camargo, P.R.; Armelin, E.; Bellotti, G.; Luz, P. da, and Décourt, L.V.: The

Relationship of Mitral Valve Prolapse to Obstructive Coronary Artery Disease. A

Hemodynamic Study 48

Case Report Mori, K.; Oonaka, M.; Tanaka, T., and Takeda, R.: Prolapsing Right Atrial

Myxoma . . 58

Varia 64

Book Review 64

No. 2

Original Paper

Wehrmacher, W.H.; Talano, J.V.; Kaye, M.P., and Randall, W.C.: The Unbalanced

Heart. Animal Models of Cardiac Dysrhythmias 65

Contents IV

Hess, M.E. and Gabel, B.E.: Dissociation between Cardiac Cyclic AMP and Myocardial Contractility Induced by Verapamil, Calcium and Magnesium Ions 75

Kyösola, K.; Partanen, S.; Penttilä, 0.; Merikallio, E.; Veijola, L., and Siltanen, P.:

Atrial Acetylcholinesterase Activity in Various Heart Diseases of Man 87

Reybrouck, T.; Amery, A.; Billiet, L., and Fagard, R.: Hemodynamic Adjustments in Hypertensive Patients Developing Circulatory Congestion during /3-Adrenergic

Blockade 97

Lin, C.I. and Vassalle, M.: Sodium Lack Prevents Strophanthidin Toxicity in Purkinje Fibers 110

Hasegawa, M. and Rodbard, S. †: Effect of Posture on Arterial Pressures, Timing of the Arterial Sounds and Pulse Wave Velocities in the Extremities 122

No. 3

Original Paper

Schmidt, H.D.; Hoppe, H., and Heidenreich, L.: Direct Effects of Dopamine, Orciprenaline and Norepinephrine on the Right and Left Ventricle of Isolated Canine Hearts 133 
Devous, M.D., Sr. and Jones, C.E.: Effect of Inosine on Ventricular Regional Perfusion and Infarct Size after Coronary Occlusion 149

Bogaert, A. van and Schepper, J. de: Influence of Some Hypotensive Drugs on the Effects of Hypothalamic Stimulation 162

Exercise Testing and Rehabilitation in Cardiology

Bartel, A.G.: Exercise Stress Testing - Current Status 170

Krasemann, E.O. and Jungmann, H.: Return to Work after Myocardial Infarction . . 190

No. 4

Original Paper

Badeer, H.S. and Rietz, R.R.: Vascular Hemodynamics: Deep-Rooted Misconceptions and Misnomers 197

Dubach, U.C.; Burckhardt, D.; Raeder, E.A.; Forgo, I.; Amrein, R., and Bückert, A.:

Effect of Intravenous Glibornuride and Tolbutamide on Myocardial Contractility . 208

Gavrilescu, S.; Gavrilescu, M.; Streian, C, and Luca, C: Complete Atrio-Ventricular

Block due to Cardiac Echinococcosis 215

Spath, J.A., Jr.; Gee, M.H., and Gwirtz, P.A.: Normalization of the Measurement of

Cardiac Creatine Phosphokinase Activity 222

Goldberg, J.M.: Differences in Atrial Septal Activation with an Intrasinoatrial Nodal

Pacemaker and Epicardial Sinoatrial Nodal Pacing 231

Contents V

Case Reports

Nesje, O.A. and Enge, I.: Impaired Rate of Left Ventricular Filling in Idiopathic

Hypertrophic Subaortic Stenosis with Atrial Fibrillation 241

Lo, K.S.; Loventhal, J.P., and Walton, J.A., Jr.: Familial Ebstein’s Anomaly 246

Exercise Testing and Rehabilitation in Cardiology

Sheps, D.S.; Gottlieb, S.; Ernst, J.C.; Kallos, N.; Briese, F.W.; Garcia, E.; Myerburg, J., and

Castellanos, A.: Effect of a Physical Conditioning Program upon Left Ventricular Ejection

Fractions Determined Serially by a Noninvasive Technique . . . 256

No. 5

Original Paper

Lefer, A.M. and Polansky, E.W.: Beneficial Effects of Ibuprofen in Acute Myocardial Ischemia 265

Steinmetz, E.; Haghfelt, T., and Thygesen, K.: Incidence and Prognostic Significance of Intraventricular Block in Acute Myocardial Infaction 280

Rissanen, V.: Sudden Coronary Death and Coronary Artery Disease. A Clinicopathologic Appraisal 289

Shapiro, J.B.: Bifascicular Block Produced by Hyperkalemia

303

Greenspan, A.M.; Morganroth, J., and Perloff, J.K.: Discrete Fibromembranous Aortic

Stenosis in Middle Age. Natural History and Case Report 306

Baudet, M.; Rigaud, M.; Rocha, P.; Bardet, J., and Bourdarias, J.P.: Reversibility of

Alcoholic Cardiomyopathy with Abstention from Alcohol 317

Exercise Testing

Manca, C; Bianchi, G.; Effendy, F.N.; Bolognesi, R.; Cucchini, F., and Visioli, O.:

Comparison of Five Different Stress Testing Methods in the ECG Diagnosis of

Coronary Artery Disease. Correlation with Coronary Arteriography

325

No. 6 
Original Paper

Thadani, U.; Chiong, M.A., and Parker, J.O.: Effects of Glucose-Insulin-Potassium

Infusion on the Angina Response during Treadmill Exercise

333

Weishaar, R.; Tschurtschenthaler, G.V.; Ashikawa, K., and Bing, R.J.: The Relationship of Regional Coronary Blood Flow to Mitochondrial Function during Reperfusion of the Ischemic Myocardium 350

Contents VI

Exercise Testing

Obma, R.T.; Wilson, P.K.; Goebel, M.E., and Campbell, D.E.: Effect of a Conditioning

Program in Patients Taking Propranolol for Angina pectoris365

Rossi, P.; Giordano, A.; Tamiz, A.; Schiavo, B., and Minuco, G.: Effects of Training

and of Verapamil on Exercise Capacity in Patients Recovering from Myocardial

Infarction. A Double-Blind Study 372

Author Index 386

Subject Index 388

Supplement 1

Pharmacokinetics and Clinical Pharmacology of Beta-Blockers in Hypertension

Sandoz Symposium on the occasion of the 8th World Congress of Cardiology, Tokyo,

September 17-23, 1978 